\title{
Interactive computational modelling to improve teaching of physics and mathematics in marine geophysics
}

Cite as: AIP Conference Proceedings 2293, 400003 (2020); https://doi.org/10.1063/5.0026601 Published Online: 25 November 2020

Rui Gomes Neves, and Maria C. Neves

\section{ARTICLES YOU MAY BE INTERESTED IN}

Physics education with interactive computational modelling AIP Conference Proceedings 2293, 400002 (2020); https://doi.org/10.1063/5.0026566

Preface of the "Symposium on Interactive Computational Modelling in Science, Technology, Engineering and Mathematics Education"

AIP Conference Proceedings 2293, 400001 (2020); https://doi.org/10.1063/5.0026569

Blow-up analysis of a parabolic system

AIP Conference Proceedings 2293, 420003 (2020); https://doi.org/10.1063/5.0027649

Challenge us.

What are your needs for periodic signal detection?

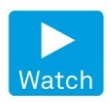

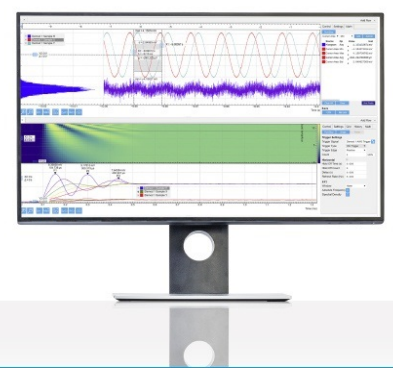

- Zurich - Instruments 


\title{
Interactive Computational Modelling to Improve Teaching of Physics and Mathematics in Marine Geophysics
}

\author{
Rui Gomes Neves ${ }^{1,2, a), b)}$ and Maria C. Neves ${ }^{3,4, c)}$ \\ ${ }^{1}$ Departamento de Ciências Económicas e Empresariais (DCEE), Universidade Autónoma de Lisboa (UAL), \\ Portugal \\ ${ }^{2}$ Unidade de Investigação Educação e Desenvolvimento (UIED), CICS.NOVA-Centro Interdisciplinar de \\ Ciências Sociais, Faculdade de Ciências e Tecnologia, Universidade Nova de Lisboa (FCT/UNL), Portugal \\ ${ }^{3}$ Instituto Dom Luiz (IDL), Faculdade de Ciências da Universidade de Lisboa (FCUL), Portugal \\ ${ }^{4}$ Universidade do Algarve (UAlg), Faculdade de Ciências e Tecnologia (FCT), Portugal \\ a)rneves@autonoma.pt \\ b)rgn@fct.unl.pt \\ c)mcneves@ualg.pt
}

\begin{abstract}
This study discusses the implementation of a learning sequence with interactive computational modelling activities in the context of introductory marine geophysics university courses. The application of two computer modelling systems, Modellus and Mirone, is considered for the introduction of mathematical physics models of interest in marine geophysics to students having only basic level knowledge of physics and mathematics and no prior knowledge of scientific computation. Modellus is used to compute the theoretical depth of the seafloor predicted using the plate cooling model, while is used to manipulate and display actual bathymetric data in the region of mid-ocean ridges. The combination of both software systems is illustrative and insightful of functionalities suitable to develop other computational modelling activities for marine geophysics as well as for other areas of the geosciences.
\end{abstract}

\section{INTRODUCTION}

Physics and mathematics are fundamental for the development of knowledge in the geosciences, thus being inevitable subjects in the corresponding courses at university level. In a significative majority of such courses, many students consider physics and mathematics difficult themes, showing fragmented knowledge states with numerous conceptual and reasoning weaknesses, even after studying and passing their examinations. This parallels situations in other areas of science, technology, engineering and mathematics (STEM) and as in these other areas also frequently leads to a decrease in student expectations about physics and mathematics [1-4]. Over the years, educational research has shown that this negative picture can be changed, and matters improved with the generation of more meaningful learning processes, if students work in atmospheres with interactive engagement activities that approximately recreate the cognitive involvement of scientists in modelling research activities [5-7].

An important didactical challenge in the implementation of these interactive research-based approaches is the appropriate integration of computational modelling into the learning processes. Indeed, in an increasing number of STEM areas modelling depends on advanced computational mathematical physics models whose elements greatly enhance the calculation, exploration, visualization, simulation and validation capabilities. Likewise, the corresponding learning processes can become more meaningful and effective with an ample use of computational modelling. In this context, we have developed and implemented an interactive engagement approach to teach physics and mathematics for STEM education that is based on sequences of interactive engagement learning activities with computational modelling that explore different kinds of modelling, from exploratory to expressive modelling, progressively introduce scientific computation without requiring prior working knowledge of programming, generate and resolve cognitive conflicts in the understanding of physics and mathematics, and

International Conference of Numerical Analysis and Applied Mathematics ICNAAM 2019

AIP Conf. Proc. 2293, 400003-1-400003-4; https://doi.org/10.1063/5.0026601

Published by AIP Publishing. 978-0-7354-4025-8/\$30.00 
comparatively analyze different and complementary representations of the mathematical models of physics [8-14]. In this previous work we have considered learning sequences built around exploratory and expressive computational modelling experiments implemented in the Modellus environment. The application contexts were those of introductory general physics or biophysics courses of various engineering university majors, and that of an introductory meteorology course involving students from a set of earth and natural sciences university majors. In this paper we extend this research to the context of introductory marine geophysics university courses.

\section{MARINE GEOPHYSICS: TEACHING CONTEXT AND COMPUTER MODELLING TOOLS}

In geophysics majors, university students are generally required to learn at least one programming language like Fortran or Python, or one scientific computation software like Matlab or Mathematica. However, when a subject such as marine geophysics is offered as an optional course to graduate students of other fields of the earth and natural sciences, or as a compulsory course to master students in marine sciences having a wide range of backgrounds, learning such advanced knowledge skills is an even more difficult cognitive process. The corresponding marine geophysics learning environments should then involve sequences of interactive computational modelling activities created with computer modelling systems able to give students the opportunity to improve their knowledge of physics, mathematics and scientific computation, while simultaneously focusing learning on the relevant earth sciences concepts. This can be achieved considering a careful application of our interactive computational modelling approach, as we briefly describe in what follows.

The specific research setting we considered was that of an introductory marine geophysics course in marine and coastal systems studies, an international master program in the University of Algarve, gathering university students having a wide range of backgrounds ranging from engineering to marine biology majors. Many of these students had only basic secondary education level knowledge about physics and mathematics and no significant prior knowledge about scientific computation. The marine geophysics classes we implemented included two complementary components: lectures where the theoretical foundations were first introduced and problem-solving lessons, based on computational modelling activities developed using freely available datasets downloaded from the internet. To build an interactive engagement environment, students worked in groups helping each other during the development of the activities. The evaluation was nevertheless performed on an individual basis. Upon completion, each student made an upload of the activity assignment in the electronic teaching platform.

The computational modelling activities were developed combining 2 computer modelling tools: Modellus [8-14] and Mirone [15]. On one hand, Modellus allowed explorative to expressive modelling involving the simultaneous manipulation and analysis of different model representations, namely, tables, graphs and animations with objects having their properties defined in a visible and modifiable mathematical physics model. On the other, Mirone allowed the display and manipulation of geophysical gridded datasets. Mirone is a Windows MATLAB-based framework tool that provides an easy-to-use graphical interface to the popular Generic Mapping Tools (GMT) package [16] and that offers a wide range of tools dedicated to topics in geophysics, such as tsunami propagation modelling, earth magnetic field computations, plate tectonic reconstructions, and seismicity plotting.

\section{AN ILLUSTRATIVE EXAMPLE: FIT THE OCEAN TOPOGRAPHY USING THE PLATE COOLING MODEL}

The extensive exploration of the seafloor in the second half of the XX century led to an improved understanding of the worldwide range of mountains on the seafloor known as mid-ocean ridges. The oceanic crust is created at mid-ocean ridges in a process known as seafloor spreading. As the seafloor spreads away from the mid-ocean ridge it gets older and experiences gradual cooling and thermal contraction. The cooling is associated with an increase in density that produces subsidence, that is, a gradual deepening of seafloor increasing with the distance from the ridge-axis. The deepening of the seafloor with age can be derived from a thermal subsidence model [17] and is approximately given by the formula $d=-d_{r}-350 \sqrt{t_{a}}$, where $d$ is the depth in meters, $d_{r}$ is the depth of the seafloor at the ridge axis and $t_{a}$ is the age of the oceanic crust in million years (Ma). The age of the crust is related to the seafloor spreading speed and to the distance from the mid-ocean ridge-axis using $t_{a}=s / v$ where $s$ is the distance to the ridge axis in $\mathrm{km}$ and $v$ is the spreading speed in $\mathrm{km} / \mathrm{Ma}$. The goal of the learning activity is to fit the 
depth-age relationship given by the above formula to actual real-world bathymetric profiles taken across mid-ocean ridges.

In the first part of the learning activity, students are asked to download the ETOPO (bedrock) data from the bathymetry and global relief maps available from the National Oceanic and Atmospheric Administration (NOAA) site (https://www.ngdc.noaa.gov). Each student selects its own geographic areas (rectangular boxes) enclosing midocean ridges. The datasets are downloaded in the GMT NetCDF grid format and subsequently loaded into the Mirone program. The next step is to use one of the Mirone tools (extract profile) to plot transects across each one of the mid-ocean ridges selected. Fig. 1 shows an example of a bathymetric map in the region of the Mid-Atlantic Ridge. The bathymetric profile can be extracted interactively by drawing a transect (dotted black line) in the perpendicular direction to the ridge, with origin at the axis. Different mid-ocean ridges spreading at different speeds give rise to different morphologies of the ocean floor. The exercise can thus be repeated considering different ridge types.

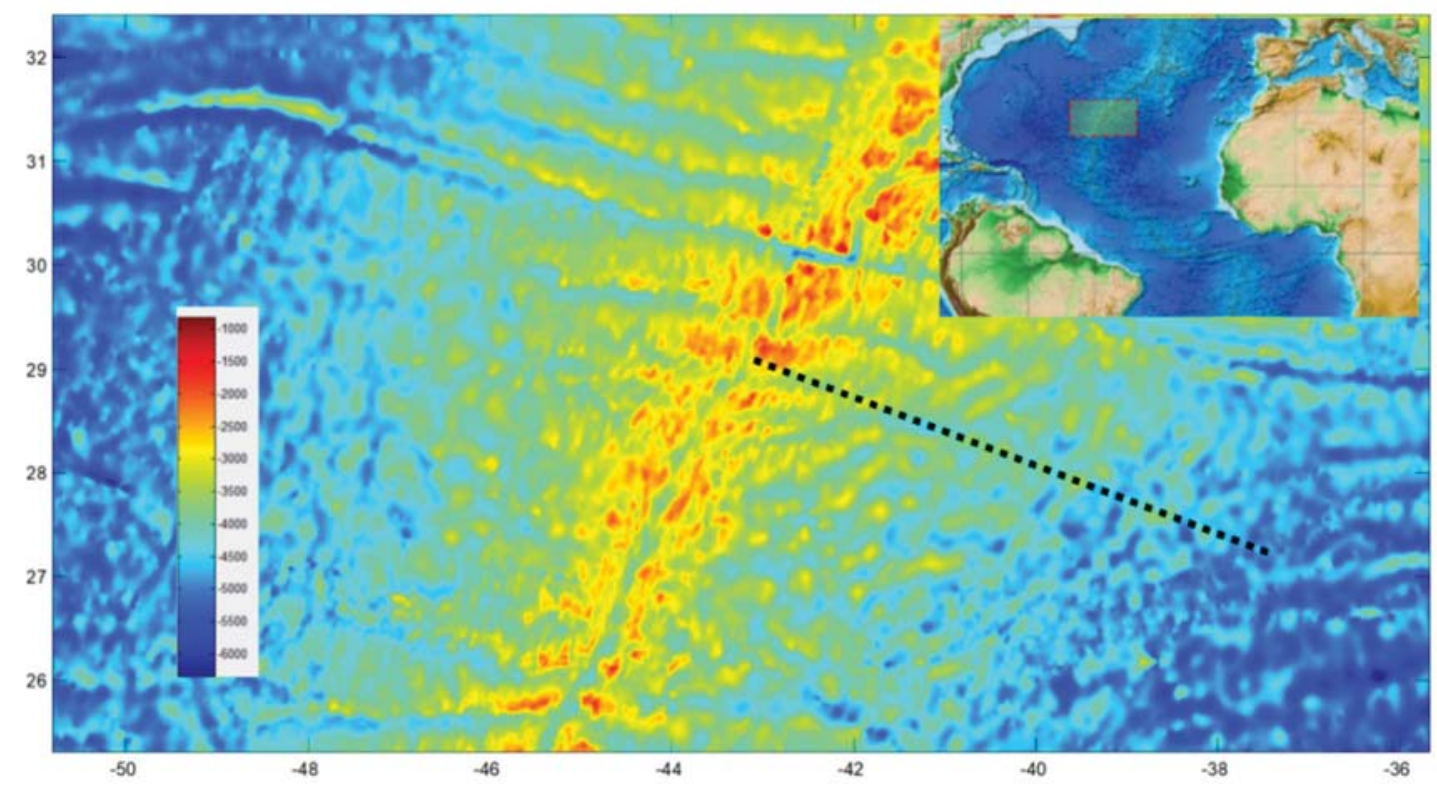

FIGURE 1. Example of a bathymetric map showing the submarine mountains that constitute the Mid-Atlantic Ridge. The inset show the rectangular box used to download the data from the NOAA site. The map is displayed using the Mirone software. The dotted black line on the map represents the transect (perpendicular to the ridge-axis) selected to extract the profile of the seafloor depth (shown in Fig. 2).

In the second part of the learning activity, students solve for the depth $d$ as a function of the age $t_{a}(s)$ using distances $s$ between 0 and $1000 \mathrm{~km}$ and a spreading speed that needs to be adjusted in order to produce the best fit to the observed bathymetry. This part of the activity is performed using Modellus. In the case of the Mid-AtlanticRidge at the selected location the best fit is obtained for $v=15 \mathrm{~km} / \mathrm{Ma}$. The accuracy of the fit can be assessed by superimposing the actual and the modelled bathymetric profiles (Fig. 2).

\section{CONCLUSIONS}

Student coursework showed that students were able to construct and explore the computational models of the marine geophysics learning sequence understanding in the process its various elements of physics, mathematics and scientific computation. An enhanced cognitive realization of how a mathematical physics analysis can be compared with observed data was achieved and shown via the combined application of two computational modelling systems, in this case Modellus and Mirone. With the inclusion of computational modelling the learning sequence has thus led 
to the development of more meaningful and operationally reified knowledge about the physics and mathematics of the plate cooling model.

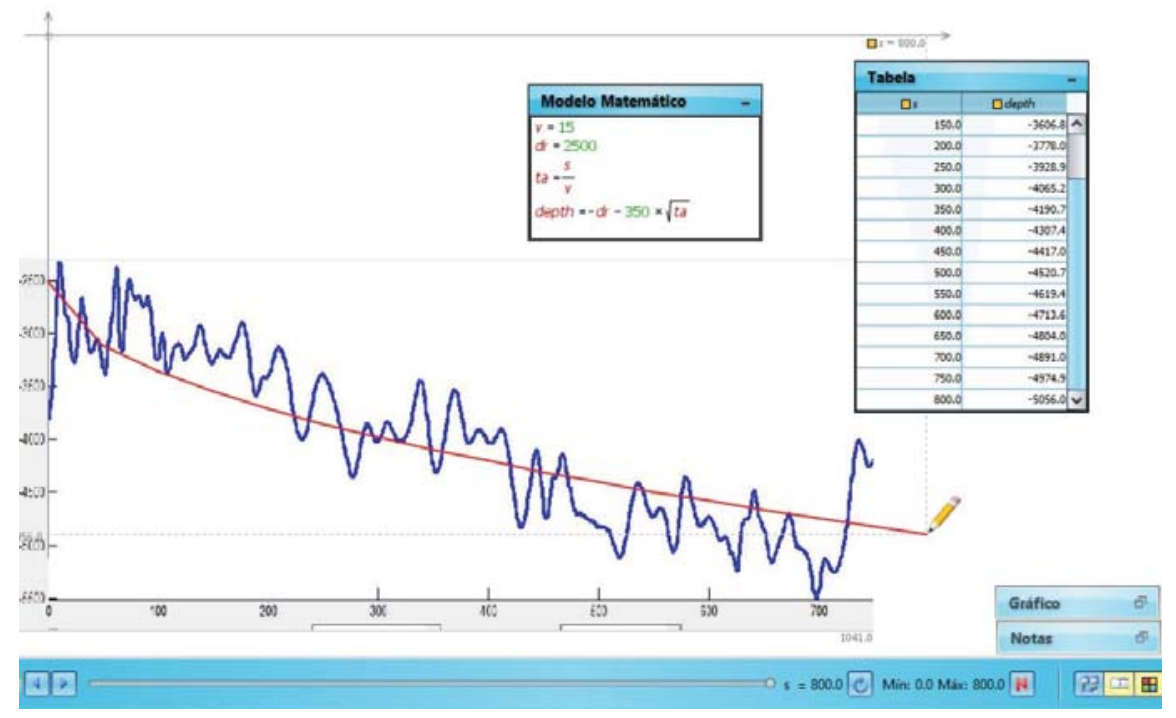

FIGURE 2. Example of a bathymetric profile perpendicular to the Mid-Atlantic Ridge. The solid line represents the actual depth of the seafloor, which decreases from near $d_{r}=2500 \mathrm{~m}$ at the ridge axis to approximately $4900 \mathrm{~m}$ at a distance of $700 \mathrm{~km}$ from the ridge axis. The dotted line represents the depth-age relationship computed from the

plate cooling model.

\section{ACKNOWLEDGEMENTS}

This work is supported by FCT- projects UID/GEO/50019/2019 and UID/CED/02861/2019.

\section{REFERENCES}

1. D. Hestenes, Am. J. Phys. 55, 440-454 (1987).

2. L. McDermott, Am. J. Phys. 59, 301-315 (1991).

3. E. Redish, J. Saul and R. Steinberg, Am. J. Phys. 66, 212-224 (1998).

4. J. Libarkin and S. Anderson, J. Geoscience Edu. 53, 394-401 (2005).

5. L. McDermott and E. Redish, Am. J. Phys. 67, 755-767 (1999).

6. K. Kortz, J. Smay and D. Murray, J. Geoscience Edu. 56, 280-290 (2008).

7. D. Meltzer and R. Thornton, Am. J. Phys. 80, 478-496 (2012).

8. R. Neves, J. Silva and V. Teodoro, "Improving Learning in Science and Mathematics with Exploratory and Interactive Computational Modelling", in International Perspectives on the Teaching and Learning of Mathematical Modelling, Vol. 1, ICTMA14 - Trends in Teaching and Learning of Mathematical Modelling, edited by G. Kaiser et al (Springer, Dordrecht, 2011), pp. 331-341.

9. V. Teodoro and R. Neves, Computer Physics Communications 182, 8-10 (2011).

10. R. Neves and V. Teodoro, AIP Conference Proceedings 1479, 1806-1809 (2012).

11. R. Neves, M. C. Neves and V. Teodoro, Computers \& Geosciences 56, 119-126 (2013).

12. R. Neves and V. Teodoro, Revista Lusófona de Educação 25, 35-58 (2013).

13. R. Neves, Revista Lusófona de Educação 35, 171-189 (2017).

14. R. Neves, AIP Conference Proceedings 2116, 410002-1-410002-4 (2019).

15. J. Luis, Computers \& Geosciences 33, 31-41 (2007).

16. P. Wessel and J. Luis, Geochem. Geophys. Geosyst. 18, 811-823 (2017).

17. D. Turcotte and G. Schutert, Geodynamics (Cambridge University Press, Cambridge, 2014). 